\title{
"The Effect of Three Different Denture Adhesives on the Growth of Micro-Organisms: in-Vivo Study."
}

\author{
Dr.Sneha Karwa ${ }^{1}$,Dr. Seema Sathe ${ }^{2}$,Dr.S R Godbole ${ }^{3}$ \\ ${ }^{1,2,3}$ (Dept. of Prosthodontics And Crown And Bridge, Sharad Pawar Dental College, Sawangi, Meghe, India)
}

\begin{abstract}
This study aims to assess the effect of three different adhesive on the colonisation of microorganisms in completely edentulous patients, by comparing colony counts of Candida species and staphylococcus in saliva of 60 patients, who were explained to use the denture without adhesives for first 14 days and then with adhesives for next 14 days. Serial dilutions were carried out upto 10-5 folds in a saline and were inoculated on to Sabouraud Dextrose agar medium and blood agar plates. All plates were incubated aerobically for $48 \mathrm{~h}$ at $37^{\circ} \mathrm{C}$. They were then examined and isolated colonies were evaluated according to their morphology and pigment formation. Statistical analysis was done. Most types of the micro-organisms were not seen and could not be analysed statistically except Candida species. No statistically significant differences were detected between groups in saliva samples for polygrip-ultradent denture adhesives. While there is statistical significant difference were detected for Ultradent- Fixodent and Polygrip-Fixodent. By using the three adhesives, the study showed that ultradent promoted the growth of micro-organisms more than the other adhesives, while fixodent promoted the least growth of micro-organisms.
\end{abstract}

Keywords: Candida albicans, Denture adhesives, Denture micro-organisms, Denture stomatitis, Saliva.

\section{Introduction}

While dealing with removable prosthesis, denture adhesives plays a very important role as an adjunct for the improvement of denture retention and stability. Denture wearers use them in order to improve chewing and mastication ability and support the patient psychologically by making their use more acceptable ${ }^{1 .}$

Sjogren's syndrome, those who are under medication or radiotherapy which may lead to xerostomia or bone resorption ${ }^{1}$. Approaches to this problem over the years, for either conventional dentures or implantsupported overdentures, have involved the use of denture adhesives ${ }^{1 .}$ Early literature says that the regular use of an appropriate adhesive reduce the likelihood of the occurrence of tissue irritation and doesnot cause any increased incidence in mucosal irritation in denture wearers and, at the same time provide the denture wearer with physical and psychological benefits ${ }^{1}$ Although clinical trials fail to show adverse effects of denture adhesives on the oral soft tissues, dentists also fear that denture adhesives cause increased alveolar ridge resorption and soft tissue hyperplasia and also patients who continue to wear such dentures may misuse denture adhesives ${ }^{1}$.

Adhesives are generally composed of rubber, pectins, methylcellulose, hydroxyl-methylcellulose, carboxylmethylcellulose, sodium-cellulose, and synthetic polymers that improve the denture support both by mechanical and physicochemical mechanisms while the additional compounds in their composition may include antimicrobial agents such as hexachlorophene, sodium tetra borate, methyl salicylate and sodium borate, additives, colorings, and preservatives ${ }^{2}$. They are available in different forms such as powders, pastes, creams, strips, as well as so-called adhesive cushions. They act by increasing the contact between the tissues and the denture and form a retentive force between the oral mucosa and the denture via an intermediary film composed of a combination of the adhesive, saliva, and other oral fluids ${ }^{2}$.

Inspite of many controversies as to whether the use of denture adhesives has an effect on bacterial growth some studies have shown that adhesives do not have an inhibitory effect upon the oral flora, while others were claimed to promote micro-organisms growth. Candida albicans is a commensal in the oral cavity of 45$65 \%$ of healthy individuals and the prevalence of Candida increases to $60-100 \%$ in denture wearers. The organism can be opportunistic, which can be explained by the fact that dentures decrease the flow of oxygen and saliva to the underlying tissue producing a local acidic and anaerobic micro-environment that favours yeast overgrowth. Additionally, poor oral hygiene and mechanical trauma from a poorly fitting denture increase the risk of tissue penetration and colonisation by Candida. Candida has affinity for the acrylic surface of dentures and its growth may lead to the development of varying degrees of denture-related stomatitis in the underlying mucosa ${ }^{3}$. However, Adisman ${ }^{4}$ stated that denture adhesives have a cushion effect and thereby prevent the food bolus going underneath the denture and eventually inhibit C. albicans growth. He et al. ${ }^{5}$ showed that Fixodent produced an in vitro reduction of denture plaque microorganisms after $8 \mathrm{~h}$ and Kim et al. ${ }^{6}$ reported that the denture adhesive tested did not significantly alter the denture microbiota during the 14-day trial period. However, longer duration of adhesive use was not studied, but Neill and Roberts ${ }^{7}$ claimed that if the general oral 
hygiene of a patient was satisfactory, then denture adhesives did not cause any bacterial growth. Also more recently, it has been suggested that the use of denture adhesives should be limited in immunologicallycompromised patients because some may cause infection in such individuals, as they contain bacterial and fungal contaminants.

\title{
1. Materials used in this study:
}

\section{Ii. Materials And Method}

1.1Three denture adhesives: Fixodent, Ultradent, Polygrip.

1.2 Blood Agar.

1.3 Sabourauds Dextrose Agar.

\author{
2. Equipments used in this study: \\ 1.1 Saliva Collector. \\ 1.2 Sterile Pipettes. \\ 1.3 Culture Plates. \\ 1.4 Incubator.
}

\section{Method}

Sixty subsequent healthy denture-wearers, age ranging between 50-65 years with healthy oral tissues referred for construction of maxillary and mandibular dentures, to Sharad Pawar Dental College, Department of Prosthodontics were involved in this study. 60 patients were divided in 3 groups with 20 patients in each group. The patients received their new conventional complete maxillary and mandibular dentures and the treatment followed a standardised protocol. For baseline microbiological measurements, during the delivery of these dentures to the patients, necessary instructions were given to the patient regarding the use and cleanliness of the dentures. Within this period, all the patients were instructed to clean their dentures and their mouth in the same manner using a normal toothbrush and soap. Patients are recalled after 14 days and saliva samples were collected in sterile saliva collector (Fig.1).

After collecting the samples at baseline, denture adhesive either Fixodent, ultradent or polygrip, randomly were given to the patients and they were instructed to use the denture adhesive for 14 days further (were considered as the control) (Fig.2).Within this period also, all the patients were instructed to clean their dentures and their mouth in the same manner using a normal toothbrush and soap. The patients were further informed not to use any other denture cleansing agent. After the use of the adhesives for 14 days, the saliva samples were evaluated microbiologically and samples were collected again from the saliva.

Microbiological evaluation: All collected samples were immediately processed for microbiological evaluation. In order to separate micro-organisms from the denture and the saliva and to achieve a homogeneous dispersion, each sample was immersed in a tube containing $1 \mu \mathrm{l}$ saline. $100 \mu \mathrm{l}$ saliva was then added into $900 \mu \mathrm{l}$ saline (Fig.3). The samples were mixed on a vortex mixer and 10 -fold serial dilutions up to $10^{-5}$ were obtained in saline. Diluted saliva sample is collected in a sterile pipettes (Fig.4). These were then inoculated on to Sabouraud Dextrose agar medium and blood agar plates using quantitative methods (Fig.5). All plates were incubated aerobically for $48 \mathrm{~h}$ at $37^{\circ} \mathrm{C}$ (Fig.6). They were then examined and isolated colonies were evaluated according to their morphology and pigment formation. Gram staining characteristics were performed. The samples were examined for the presence of Candida species and Staphylococci under microscope (Fig.7).

\section{Iv. Observations And Results}

All the data was recorded, tabulated and subjected to statistical analysis. Statistical analysis was done by using descriptive and inferential statistics using Krushkal Wallis Chisquare test, student's paired t test and Mann Whitney U test. Software used in the analysis were SPSS 17.0 version and EPI INFO 7.0 version and $\mathrm{p}<0.05$ is considered as level of significance.

Results were obtained and graph were plotted as Graph 1, Graph 2, Graph 3 and Graph 4. Significant values were obtained as in Table 1, Table 2, Table 3 and Table 4.

\section{Discussion}

The present study was undertaken with the aim of clarifying the effect of three commercially available denture adhesives on micro-organisms growth-in vivo. In principle, ideally when a denture is made, there should be no need for a denture adhesive. However, in patients where saliva flow is impaired due to diseases or medication, where anatomical structures are not favourable, in order to compensate for technical failures during denture processing denture adhesives can be used as a potential aid to improve denture retention and stability ${ }^{\mathrm{P}}$. No retention and stability of complete dentures has frequently caused a high degree of dissatisfaction in denture wearers, especially in the mandible because of the limited dimensions of mandibular prostheses and a complex 
oral and tongue musculature. In the maxilla, the presence of a nonmobile keratinized mucosa, the absence of significant muscle pull, and a wide contact surface provide a reasonable degree of support, stability, and retention of the prosthesis, in spite of the force of gravity ${ }^{2}$.

In this study, the micro-organisms seen were Candida and staphylococcus. Some of the gram positive bacilli, gram negative cocci, gram negative rods and streptococcus were also found in this study. No statistically significant differences were detected between groups in saliva samples for polygrip- ultradent denture adhesives. While there is statistical significant difference were detected for Ultradent- Fixodent and Polygrip -Fixodent.

Though C. albicans, is a common oral organism, its estimates suggest the presence in $40 \%$ of the normal populations and in $50 \%$ of patients in dental hospitals. $\mathrm{C}$ albicans and denture stomatitis has a relationship amongst them. Since hyphal formation was observed and the finding that all the adhesives examined supported growth of this organism, so C. albicans is of some more importance. Oral smears do not normally show mycelium formation, and this characteristic is a feature of the pathogenic condition. Evidence that concerns the relationship is conflicting between other dental materials and the growth of C. albicans ${ }^{8}$. Denture-induced stomatitis is an inflammatory lesion of the denture bearing mucosa that affects approximately $50 \%$ of patients wearing complete maxillary dentures and has a multifactorial aetiology. In addition to Candida spp., other pathogenic and opportunistic micro-organisms have also been isolated from patient's dentures including Staphylococcus species, gram positive and gram negative cocci and Pseudomonas species, etc. but this study mainly aims at Candida and Staphylococcus species ${ }^{1}$.

Prosthesis retention and stability can be improved with the use of denture adhesives have been reported by several studies. The studies showed a significant improvement when adhesives were used. A survey by Slaughter et al. using the Delphi Technique Survey Method was conducted using a panel of 18 randomly selected prosthodontic programme directors in the USA. The panel concluded that denture adhesives could be seen as a useful adjunct in the denture prosthodontic service ${ }^{1}$. Patients generate significantly greater levels of incisal bite force 8 hours after application with the use of an adhesive. These increases were on the order of 20 $\mathrm{N}$, from approximately $35 \mathrm{~N}$ at baseline to a maximum of $54 \mathrm{~N}$ at 8 hours after application. These improvements are interpreted to reflect an increased level of confidence associated with the use of the adhesive. This reason explain why patients report an increased ability to bite hard foods (corn ,apple, carrot) when they use an adhesive ${ }^{9}$.

The accurate technical construction of the prosthesis and the psychologic aspects of treatment is very important in the management of complete denture patients. All patients completed a structured questionnaire after regular use of their dentures with the assigned adhesive. Only $8 \%$ of patients reported difficulties in eliminating the remnants of the adhesive while most of the patients found the adhesives easy or very easy to use,. The retention of the denture with the use of the adhesive was either good or very good according to $84 \%$ of patient ${ }^{2}$. . The indication for denture adhesives is not seen as a danger in some countries, in others the use of such adhesives is strictly avoided. The major reason for this is the microbiological concerns in the case of uncontrolled prolonged use of the adhesives ${ }^{1}$.

\section{Conclusion}

Within the limitations of the study's design (ie, size, power, diversity, time-dependence considerations) together with the selection of a specific patient population group, it was found that denture adhesives improve the stability and retention of the complete denture-wearing experience. The three tested adhesives were efficacious but no statistically significant differences were detected between groups in saliva samples for polygrip- ultradent denture adhesives, while there is statistical significant difference were detected for Ultradent- Fixodent and Polygrip -Fixodent.

\section{Limitations}

An important limitation of this study is that in vivo observations are not always reproducible in vitro; saliva components and salivary flow as well as the variable salivary $\mathrm{pH}$ can interfere with $\mathrm{C}$. albicans growth. Also, other factors such as trauma, inflammatory state and the presence of additional patho-physiological conditions need to be taken into account. For example, in one in vivo investigation, denture stomatitis decreased with denture adhesives by associating the reduction of Candida with reduced trauma. 


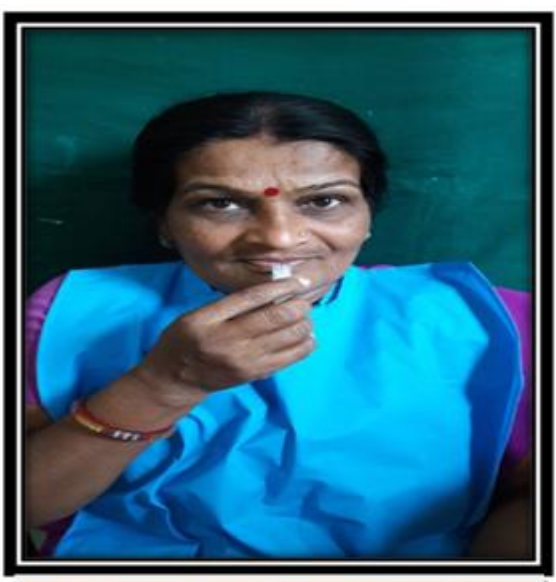

fig. 1 collection of saliva samble

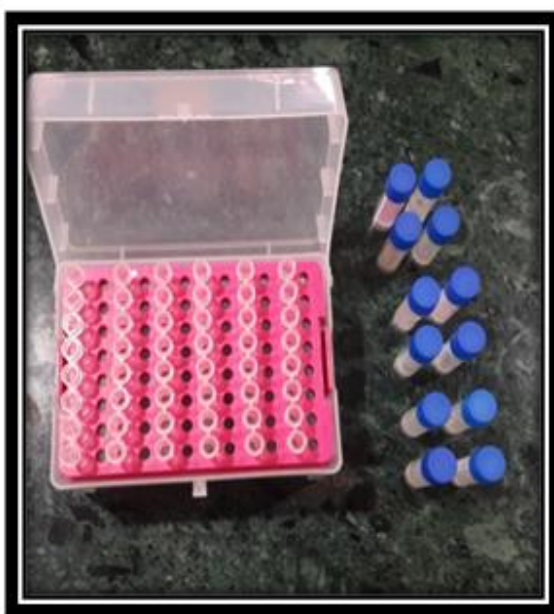

fig 3 serial dilution upto $10^{-5}$ folds

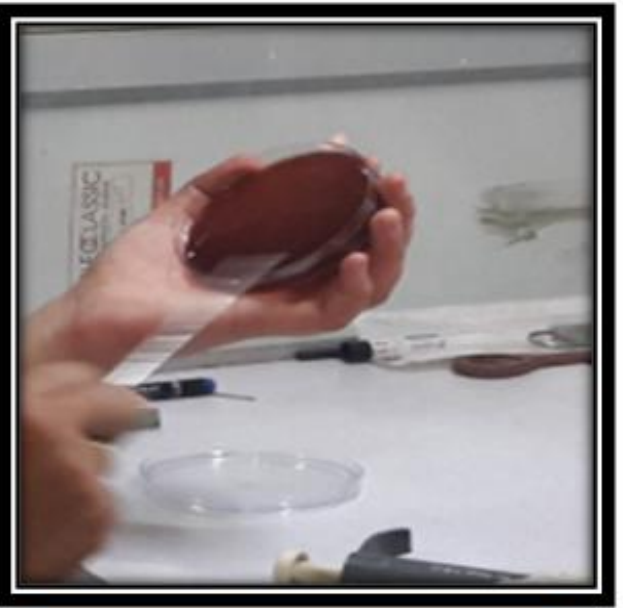

fig. 5 culture plating on agar plates

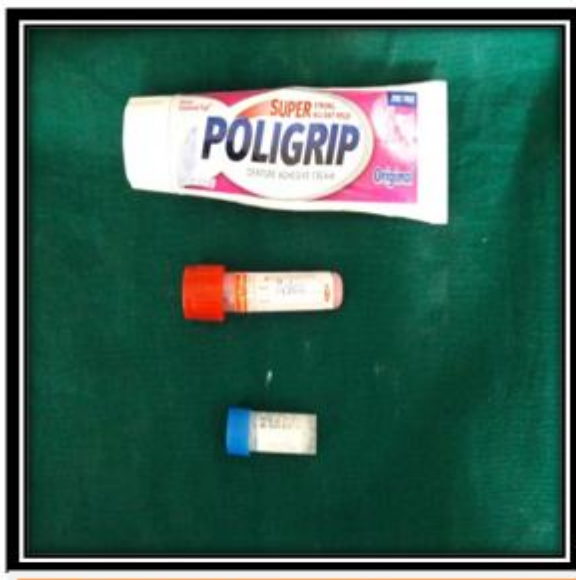

fig. 2 denture adhesive delivery to the patient

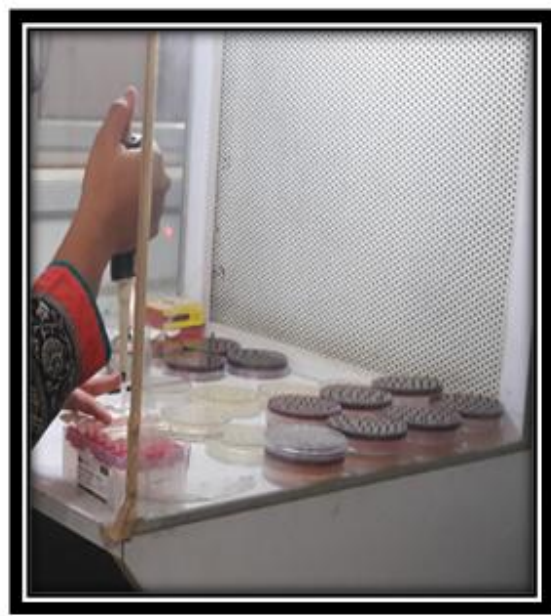

fig. 4 collection of diluted saliva samples in a sterile pipettes sample

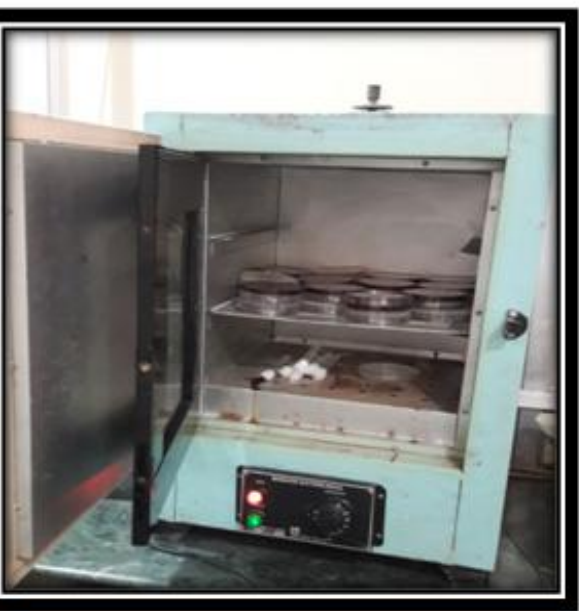

fig. 6 incubation of agar plates at $37^{\circ} \mathrm{C}$ for $48 \mathrm{hrs}$. 


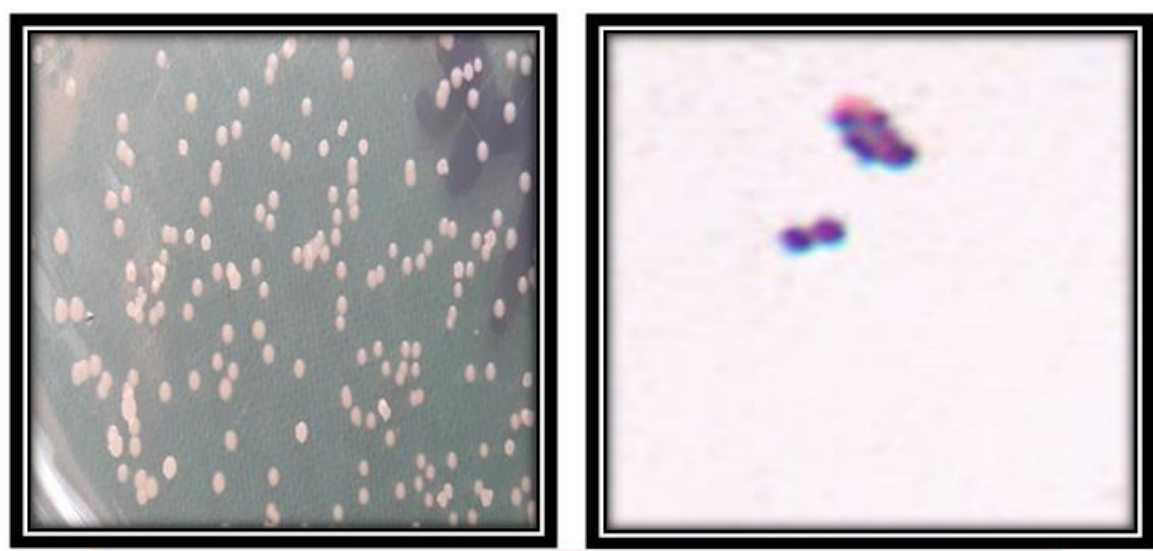

fig. 7 candida and staphylococcus colonies under microscope

table 1: effect of three denture adhesives on growth of microorganisms on blood agar - descriptive Statistics.

\begin{tabular}{|c|c|c|c|c|c|}
\hline & & Mean & $\mathrm{N}$ & Std. Deviation & Std. Error Mean \\
\hline \multirow{2}{*}{ Polygrip } & Without adhesive & 23.33 & 3 & 2.88 & 1.66 \\
\cline { 2 - 6 } & With adhesive & 30.00 & 3 & 0.00 & 0.00 \\
\hline \multirow{2}{*}{ Ultradent } & Without adhesive & 51.66 & 3 & 2.88 & 1.66 \\
\cline { 2 - 6 } & With adhesive & 58.33 & 3 & 2.88 & 1.66 \\
\hline \multirow{2}{*}{ Fixodent } & Without adhesive & 1.66 & 3 & 2.88 & 1.66 \\
\cline { 2 - 6 } & With adhesive & 2.33 & 3 & 4.04 & 2.33 \\
\hline
\end{tabular}

Student's paired t test

\begin{tabular}{|c|c|c|c|c|c|c|c|c|}
\hline & \multicolumn{5}{|c|}{ Paired Differences } & \multirow[t]{3}{*}{$\mathrm{t}$} & \multirow[t]{3}{*}{ df } & \multirow{3}{*}{$\mathrm{p}$-value } \\
\hline & & & & \multicolumn{2}{|c|}{$\begin{array}{l}95 \% \text { Confidence } \\
\text { Interval of the } \\
\text { Difference }\end{array}$} & & & \\
\hline & Mean & $\begin{array}{c}\text { Std. } \\
\text { Deviation } \\
\end{array}$ & $\begin{array}{c}\text { Std. Error } \\
\text { Mean }\end{array}$ & $\begin{array}{c}\text { Lowe } \\
\mathrm{r}\end{array}$ & Upper & & & \\
\hline Polygrip & 6.66 & 2.88 & 1.66 & 0.50 & 13.83 & 4.00 & 2 & $0.057, \mathbf{N S}, \mathrm{p}>0.05$ \\
\hline Ultradent & 6.66 & 2.88 & 1.66 & 0.50 & 13.83 & 4.00 & 2 & $0.057, \mathbf{N S}, \mathrm{p}>0.05$ \\
\hline Fixodent & .66 & 1.15 & 0.66 & 2.20 & 3.53 & 1.00 & 2 & $0.423, \mathrm{NS}, \mathrm{p}>0.05$ \\
\hline
\end{tabular}

Graph 1: Mean of effect of three denture adhesives on growth of microorganisms on blood agar.

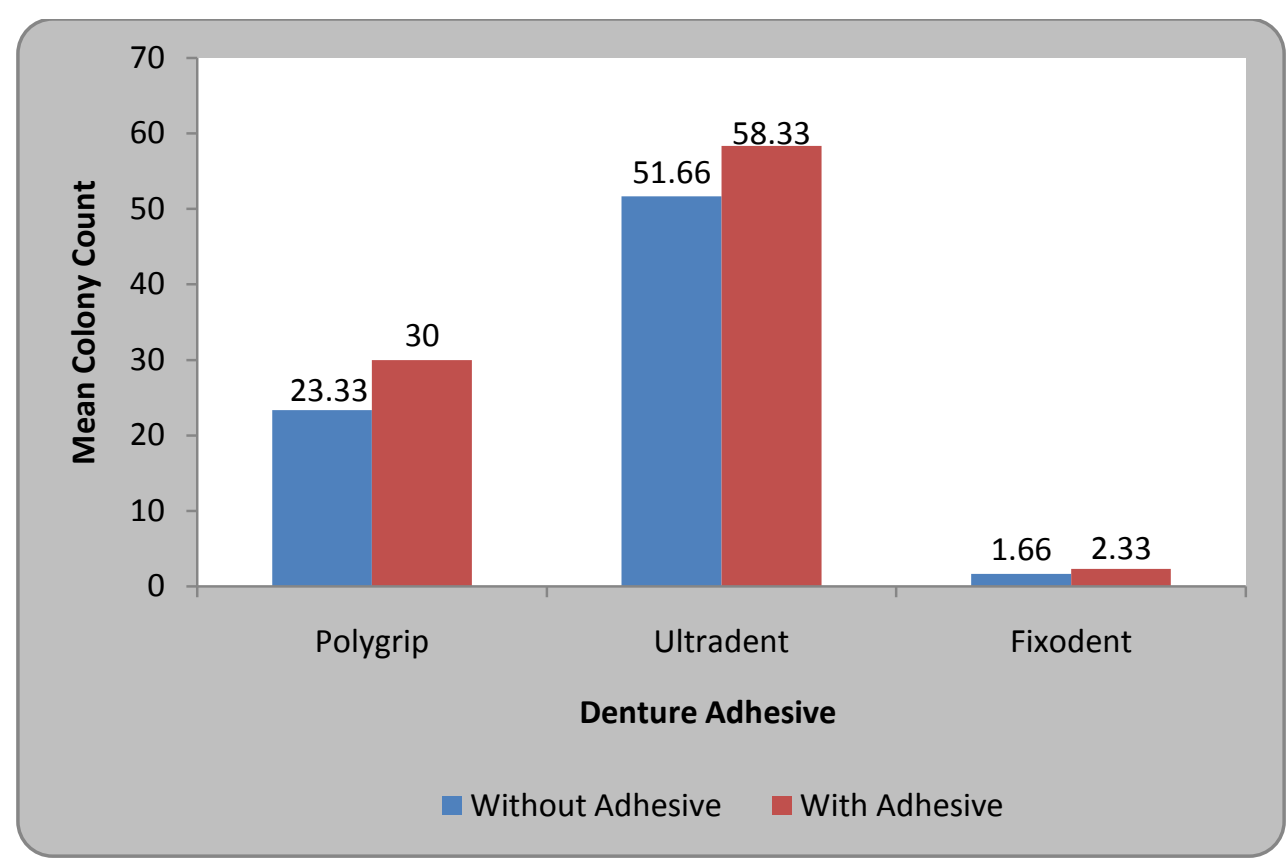


"The Effect Of Three Different Denture Adhesives On The Growth Of Micro....

Table 2: Effect of three denture adhesives on growth of microorganisms on SDA - Descriptive Statistics.

\begin{tabular}{|c|c|c|c|c|c|}
\hline & & Mean & $\mathrm{N}$ & Std. Deviation & Std. Error Mean \\
\hline \multirow{2}{*}{ Polygrip } & Without adhesive & 18.33 & 3 & 2.88 & 1.66 \\
\cline { 2 - 6 } & With adhesive & 25.00 & 3 & 5.00 & 2.88 \\
\hline \multirow{3}{*}{ Ultradent } & Without adhesive & 24.33 & 3 & 1.15 & 0.66 \\
\cline { 2 - 6 } & With adhesive & 31.66 & 3 & 2.88 & 1.66 \\
\hline \multirow{2}{*}{ Fixodent } & Without adhesive & 4.33 & 3 & 1.15 & 0.66 \\
\cline { 2 - 6 } & With adhesive & 5.66 & 3 & 1.15 & 0.66 \\
\hline
\end{tabular}

Student's paired t test

\begin{tabular}{|c|c|c|c|c|c|c|c|c|}
\hline & \multicolumn{5}{|c|}{ Paired Differences } & \multirow[t]{3}{*}{$\mathrm{t}$} & \multirow[t]{3}{*}{$\mathrm{df}$} & \multirow[t]{3}{*}{$\mathrm{p}$-value } \\
\hline & & & & \multicolumn{2}{|c|}{$\begin{array}{l}95 \% \text { Confidence } \\
\text { Interval of the } \\
\text { Difference }\end{array}$} & & & \\
\hline & $\begin{array}{c}\text { Mea } \\
\mathrm{n}\end{array}$ & $\begin{array}{c}\text { Std. } \\
\text { Deviation }\end{array}$ & $\begin{array}{l}\text { Std. } \\
\text { Error } \\
\text { Mean }\end{array}$ & Lower & $\begin{array}{l}\text { Uppe } \\
\text { r }\end{array}$ & & & \\
\hline Polygrip & 6.66 & 2.88 & 1.66 & 0.50 & 13.83 & 4.000 & 2 & $\begin{array}{c}0.057, \mathbf{N S}, \mathrm{p}>0 . \\
05\end{array}$ \\
\hline Ultradent & 7.33 & 4.04 & 2.33 & 2.70 & 17.37 & 3.143 & 2 & $\begin{array}{c}0.088, \mathbf{N S}, \mathrm{p}>0 . \\
05\end{array}$ \\
\hline Fixodent & 1.33 & 1.15 & 0.66 & 1.53 & 4.20 & 2.000 & 2 & $\begin{array}{c}0.184, \mathbf{N S}, \mathrm{p}>0 . \\
05\end{array}$ \\
\hline
\end{tabular}

Graph 2: Mean of effect of three denture adhesives on growth of microorganisms on SDA.

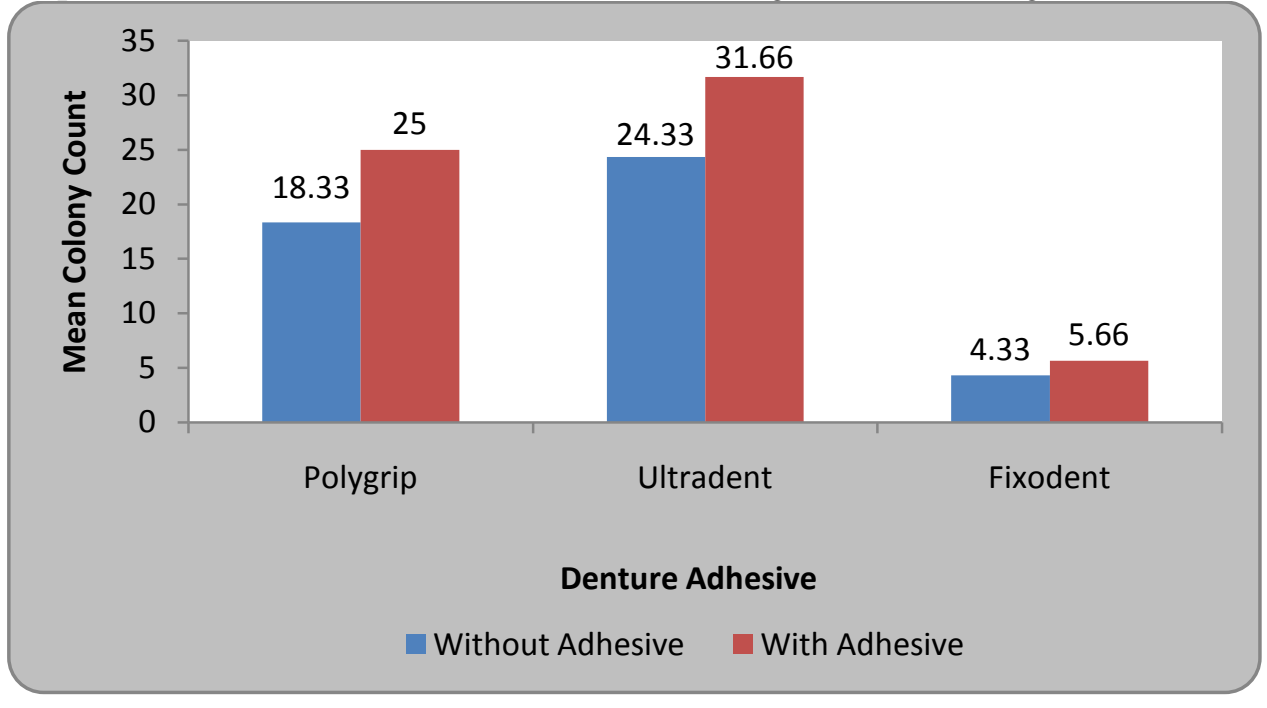

Table 3: Comparison of the effectiveness of three adhesives of blood agar - Descriptive Statistics.

\begin{tabular}{|c|c|c|c|c|c|c|c|c|}
\hline & \multirow{2}{*}{$\mathrm{N}$} & \multirow{2}{*}{ Mean } & Std. Deviation & \multirow{2}{*}{ Std. Error } & \multicolumn{2}{|c|}{$\begin{array}{c}\text { Confidence Interval } \\
\text { for Mean }\end{array}$} & \multirow{2}{*}{ Minimum } & Maximum \\
\cline { 6 - 9 } & & & & $\begin{array}{c}\text { Lower } \\
\text { Bound }\end{array}$ & $\begin{array}{c}\text { Upper } \\
\text { Bound }\end{array}$ & & \\
\hline Polygrip & 3 & 30.00 & 0.00 & 0.00 & 30.00 & 30.00 & 30.00 & 30.00 \\
\hline Ultradent & 3 & 58.33 & 2.88 & 1.66 & 51.16 & 65.50 & 55.00 & 60.00 \\
\hline Fixodent & 3 & 2.33 & 4.04 & 2.33 & -7.70 & 12.37 & 0.00 & 7.00 \\
\hline
\end{tabular}

- Krushkal Wallis Chisquare value=286.06,p-value=0.0001,S Multiple Comparison : Mann Whitney U test

\begin{tabular}{|c|c|c|c|c|c|c|}
\hline \multicolumn{7}{|c|}{ Multiple comparisons } \\
\hline & & \multirow{2}{*}{$\begin{array}{c}\text { Mean } \\
\text { Difference (I-J) }\end{array}$} & \multirow[t]{2}{*}{ Std. Error } & \multirow[t]{2}{*}{ p-value } & \multicolumn{2}{|c|}{$95 \%$ Confidence Interval } \\
\hline & & & & & Lower Bound & Upper Bound \\
\hline \multirow[t]{2}{*}{$\begin{array}{c}\text { Polygri } \\
\text { p }\end{array}$} & $\begin{array}{c}\text { Ultraden } \\
t\end{array}$ & 28.33 & 2.34 & $0.0001 \mathrm{~S}, \mathrm{p}<0.05$ & 21.14 & 35.51 \\
\hline & Fixodent & 27.66 & 2.34 & $0.0001 \mathbf{S}, \mathrm{p}<0.05$ & 20.48 & 34.85 \\
\hline $\begin{array}{c}\text { Ultrade } \\
\text { nt }\end{array}$ & Fixodent & 56.00 & 2.34 & $0.0001 \mathrm{~S}, \mathrm{p}<0.05$ & 48.81 & 63.18 \\
\hline
\end{tabular}


Graph 3: Mean of comparison of the effectiveness of three adhesives of blood agar.

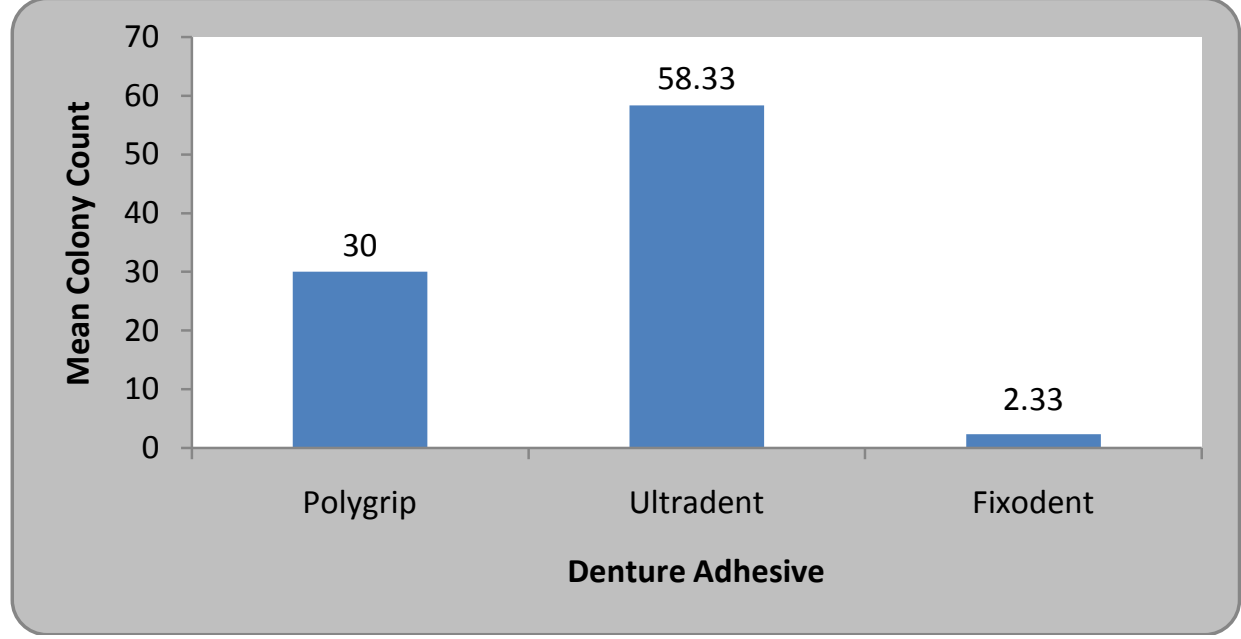

Table 4: Comparison of the effectiveness of three adhesives of SDA - Descriptive Statistics.

\begin{tabular}{|c|c|c|c|c|c|c|c|c|}
\hline & \multirow{2}{*}{$\mathrm{N}$} & \multirow{2}{*}{ Mean } & \multirow{2}{*}{ Std. Deviation } & \multirow{2}{*}{ Std. Error } & \multicolumn{2}{|c|}{$\begin{array}{c}\text { 95\% Confidence Interval for } \\
\text { Mean }\end{array}$} & \multirow{2}{*}{ Minimum } & \multirow{2}{*}{ Maximum } \\
\hline & & & & & Lower Bound & $\begin{array}{l}\text { Upper } \\
\text { Bound }\end{array}$ & & \\
\hline Polygrip & 3 & 25.00 & 5.00 & 2.88 & 12.57 & 37.42 & 20.00 & 30.00 \\
\hline Ultradent & 3 & 31.66 & 2.88 & 1.66 & 24.49 & 38.83 & 30.00 & 35.00 \\
\hline Fixodent & 3 & 5.66 & 1.15 & 0.66 & 2.79 & 8.53 & 5.00 & 7.00 \\
\hline
\end{tabular}

- Krushkal Wallis Chisquare value=47.34,p-value=0.0001,S Multiple Comparison : Mann Whitney U test

\begin{tabular}{|l|l|l|l|l|l|l|}
\hline \multicolumn{2}{|c|}{} & $\begin{array}{l}\text { Mean Difference } \\
\text { (I-J) }\end{array}$ & $\begin{array}{l}\text { Std. } \\
\text { Error }\end{array}$ & p-value & \multicolumn{2}{|l|}{ 95\% Confidence Interval } \\
\cline { 4 - 7 } & & & & Lower Bound & $\begin{array}{l}\text { Upper } \\
\text { Bound }\end{array}$ \\
\hline \multirow{2}{*}{ Polygrip } & Ultradent & -6.66 & 2.77 & $0.116, \mathbf{N S}, \mathrm{p}>0.05$ & 1.84 & 15.18 \\
\cline { 2 - 7 } & Fixodent & 19.33 & 2.77 & $0.001 \mathbf{S}, \mathrm{p}<0.05$ & 10.81 & 27.84 \\
\hline Ultradent & Fixodent & 26.00 & 2.77 & $0.0001 \mathrm{~S}, \mathrm{p}<0.05$ & 17.48 & 34.516 \\
\hline
\end{tabular}

Graph 4: Mean of comparison of the effectiveness of three adhesives of SDA.

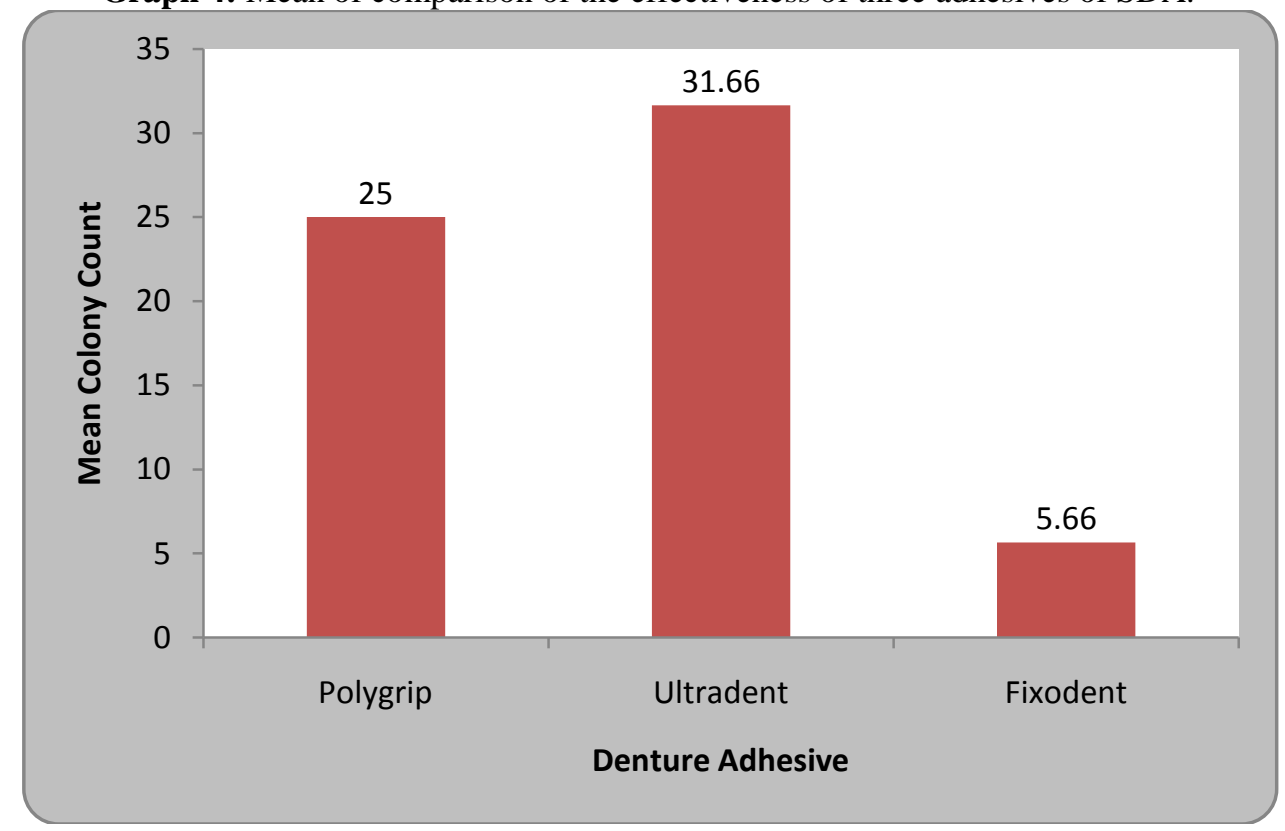




\section{References}

[1]. Yasemin Kulak Ozkan1, Mert Uc sankale1, Mutlu O“ zcan2 and Nurver U“ ner, Effect of denture adhesive on the micro-organisms in vivo ( _ 2011 The Gerodontology Society and John Wiley \& Sons A/S, Gerodontology 2012; 29: 9-16).

[2]. Guillermo Pradíes, DDS, Dr Odonta/Ignacio Sanz, DDSb/Ofelia Evans, DDSc/ Francisco Martínez, DDS, Dr Odontd/Mariano Sanz, MD, DDS, Dr Mede, Clinical Study Comparing the Efficacy of Two Denture Adhesives in Complete Denture Patients. The International Journal of Prosthodontics 2009; 361-367.

[3]. Benedita Sampaio-Maia1, Maria Helena Figueiral1, Patricia Sousa-Rodrigues1, Maria Helena Fernandes1 and Crispian Scully, The effect of denture adhesives on Candida albicans growth in vitro ( _ 2011 The Gerodontology Society and John Wiley \& Sons A/S, Gerodontology 2012; 29: e348-e356).

[4]. Adisman IK., The use of denture adhesives as an aid to denture treatment. J Prosthet Dent 1989;62:711-715.

[5]. He T, Zhou X, Becus MS et al. ,Plaque inhibition with denture adhesive use. J Dent Res 2002; 81: 459.

[6]. Kim E, Driscoll CF., The effect of a denture adhesive on the colonization of Candida species in vivo. J Prosthodont 2004; 12: 187191.

[7]. Neill DJ, Roberts BJ., The effect of denture fixatives on masticatory performance in complete denture patients. J Dent 1973; 1: 219222 .

[8]. G. D. STAFFORD* and C. RUSSELL., Efficiency of denture adhesives and their possible influence on oral microorganisms the Turner Dental School, Bridgeford Street, Manchester 15, England . I Dent Res July-August 1969;832-836.

[9]. Grasso JE., Effect of Denture adhesives on retention and stability of maxillary dentures Joseph R Grasso,DDS, MSD, Jill Rendell, MPH, and Thomas Gay, PhD School of Dental Medicine, Univcrsity of Cormecticut Health Center, Farmington, Conn.. J Of Prosthetic Dentistry; Oct 1994;399-405.

[10]. Oliveira MC, Oliveira VM, Vieira AC et al., In vivo assessment of the effect of an adhesive for complete dentures on colonisation of Candida species. Gerodontology 2010; 27: 303-307.

[11]. Eunghwan Kim, DDS, MS1, Carl F, Driscoll, DMD2, and Glenn E, Minah, DDS, PhD- The effect of a denture adhesive on the colonization of Candida species in vivo, (Journal of Prosthodontics, Vol 12, No 3,(September), 2003: pp 187-191).

[12]. Abdelmalek RG, Michael CG.,The effect of denture adhesives on the palatal mucosa under complete dentures. A clinical and histological investigation. Egypt Dent J 1978;24:419-430.

[13]. Mario C. S. Oliveira1, Viviane M. B. Oliveira2, Alex C. Vieira3 and Isabel Rambob4- In vivo assessment of the effect of an adhesive for complete dentures on colonisation of Candida species ( _ 2009 The Authors Journal compilation _ 2009 The Gerodontology Society and John Wiley \& Sons A/S, Gerodontology 2010; 27: 303-307 303).

[14]. Makihira S, Nikawa H, Satonobu SV et al., Growth of Candida species on commercial denture adhesives in vitro.( Int J Prosthodont 2001; 14: 48-52_)

[15]. Gates WD, Goldschmidt M, Kramer D. Microbial contamination in four commercially available denture adhesives. J Prosthet Dent 1994; 71: 154-158.

[16]. Seicho Makihira, DDS, PhDa Hiroki Nikawa, DDS, PhDb Silvia Veronica Satonobu, DDSc Chen Jin, DDSd Taizo Hamada, DDS, PhDe- Growth of Candida Species on Commercial Denture Adhesives In Vitro (The International Journal of Prosthodontics, Volume 14, Number 1, 2001; 48-52). 